\title{
Erratum to: Cancer stem-like cells enriched with CD29 \\ and CD44 markers exhibit molecular characteristics \\ with epithelial-mesenchymal transition in squamous cell carcinoma
}

\author{
Songmei Geng ${ }^{1} \cdot$ Yuanyuan Guo $^{1} \cdot$ Qianqian Wang $^{1} \cdot$ Lan $^{1}{ }^{1} \cdot$ Jianli Wang $^{2}$
}

Published online: 7 April 2017

(C) Springer-Verlag Berlin Heidelberg 2017

\section{Erratum to: Arch Dermatol Res (2013) 305:35-47}

DOI 10.1007/s00403-012-1260-2

The second sentence in the second paragraph under section "Immunohistochemical analysis in SCC tissues" in "Materials and methods" heading was incorrectly published. The correct sentence should read as follows:

After quenching of endogenous peroxidase activity with $\mathrm{H}_{2} \mathrm{O}_{2}$ and blocking with normal goat serum, the sections were incubated with rabbit anti-CD29 antibody (Santa Cruz, USA) diluted at 1:50 and mouse anti-CD44 antibody (No. 3570, Cell Signaling Technology, USA) diluted at 1:100 separately overnight at $4{ }^{\circ} \mathrm{C}$.

The online version of the original article can be found under doi:10.1007/s00403-012-1260-2.

Songmei Geng

gsm312@yahoo.com

1 Department of Dermatology, Northwest Hospital, Xi' an Jiaotong University, Xi' an 710004, China

2 Department of Hematology, Northwest Hospital, Xi' an Jiaotong University, Xi' an 710004, China 